\title{
A study of bonding and failure mechanisms in fuel pellets from different biomass resources
}

Stelte, Wolfgang; Holm, Jens K.; Sanadi, Anand R.; Barsberg, Søren; Ahrenfeldt, Jesper; Henriksen, Ulrik Birk

Published in:

Biomass \& Bioenergy

Link to article, DOI:

10.1016/j.biombioe.2010.11.003

Publication date:

2011

Link back to DTU Orbit

Citation (APA):

Stelte, W., Holm, J. K., Sanadi, A. R., Barsberg, S., Ahrenfeldt, J., \& Henriksen, U. B. (2011). A study of bonding and failure mechanisms in fuel pellets from different biomass resources. Biomass \& Bioenergy, 35(2), 910-918. https://doi.org/10.1016/j.biombioe.2010.11.003

\section{General rights}

Copyright and moral rights for the publications made accessible in the public portal are retained by the authors and/or other copyright owners and it is a condition of accessing publications that users recognise and abide by the legal requirements associated with these rights.

- Users may download and print one copy of any publication from the public portal for the purpose of private study or research.

- You may not further distribute the material or use it for any profit-making activity or commercial gain

- You may freely distribute the URL identifying the publication in the public portal 


\title{
A study of bonding and failure mechanisms in fuel pellets from different biomass resources
}

\author{
Wolfgang Stelte ${ }^{a^{*}}$, Jens K. Holm ${ }^{b}$, Anand R. Sanadi ${ }^{c}$, Søren Barsberg ${ }^{c}$, Jesper Ahrenfeldt ${ }^{a}$ and Ulrik B. \\ Henriksen $^{a}$ \\ *Corresponding author: Phone: +45 4677 4183, Fax: +45 4677 4109, E-mail: wost@risoe.dtu.dk \\ ${ }^{a}$ Biosystems Division, Risø National Laboratory for Sustainable Energy, Technical University of Denmark-DTU, \\ Frederiksborgvej 399, DK 4000, Roskilde, Denmark, \\ ${ }^{b}$ Chemical Engineering, DONG Energy Power A/S, A.C. Meyers Vange 9, DK 2450, Copenhagen SV, Denmark. \\ ${ }^{c}$ Forest \& Landscape Denmark, Faculty of Life Sciences, University of Copenhagen, Rolighedsvej 23, DK-1985 \\ Frederiksberg C, Denmark.
}

Pelletization of biomass reduces its handling costs, and results in a fuel with a greater structural homogeneity. The aim of the present work was to study the strength and integrity of pellets and relate them to the quality and mechanisms of inter-particular adhesion bonding. The raw materials used were: beech, spruce and straw, representing the most common biomass types used for fuel pellet production, i.e. hardwoods, softwoods and grasses, respectively. The results showed that the compression strengths of the pellets were in general higher for pellets produced at higher temperatures, and much higher for wood pellets than for straw pellets. Scanning electron microscopy of the beech pellets fracture surfaces, pressed at higher temperatures, showed areas of cohesive failure, indicating high energy failure mechanisms, likely due to lignin flow and inter-diffusion between adjacent wood particles. These were absent in both spruce and straw pellets. Infrared spectroscopy of the fracture surfaces of the straw pellets indicated high concentrations of hydrophobic extractives, that were most likely responsible for their low compression strength, due to presence of a chemical weak boundary layer, limiting the adhesion mechanism to van der Waals forces. Electron micrographs indicating interfacial failure mechanisms support these findings. Infrared spectra of the fracture surface of wood pellets, pressed at elevated temperatures, showed no signs of hydrophobic extractives. 
It has been shown that both temperature and chemical composition, i.e. the presence of hydrophobic extractives, have a significant influence on the bonding quality between biomass particles during the pelletizing process.

Key words: Biomass, Pellet, Bonding, Adhesion, Fracture surface, Weak boundary layer

\section{Introduction}

The handling of large biomass quantities is work and energy intensive, and therefore one of the major cost factors limiting the utilization of plant biomass as a source for sustainable heat and energy production. The distance between the place of origin of the biomass, and the location where it is used for energy production, is often great which leads to expensive logistics. Mechanical densification of biomass into fuel pellets has been shown to significantly reduce storage, and transportation costs [1]. Furthermore its energy density is increased, and pellets are more homogeneous in size and structure than the raw biomass, enabling automated feeding in continuous boiler systems. Fuel pellets are used both in industrial sized heat and power production (CHP) plants, thermal gasification units, as well as for heating in private households. The global pellet market is growing strongly, and the global annual production of wood pellets was recently estimated by the International Energy Agency (IEA) to be at about 6 to 8 million tons, with a net potential of about 13 million tons [2]. The raw materials used for biomass pellet production today, are mainly wood residues, such as wood shavings, saw dust and wood chips, while agro-residues, energy crops and waste products from the food industry are becoming increasingly important [3]. The utilization of grasses, either as residues from the cultivation of grains, or as energy crops, has recently been of great interest as a source for fuel pellet production.

Biomass from plants is a cellular material of high porosity, as the plant cells interior consists mainly of a large vacuole filled with water, or air in case of dried biomass. The plant cell wall is a composite material consisting of the amorphous polymers lignin, hemicelluloses and partly crystalline cellulose as reinforcement. In addition, minor amounts of extraneous materials can be found [4]. Cellulose is the major component of plant biomass, and is a high molecular weight, linear polymer consisting of $\beta-1,4$ linked glucose units. It is arranged into ordered strands of high crystallinity, often referred to as microfibrils [5]. Along with the other wood components, they are organized into fibers that form the major structural unit of the plant cell wall. The cellulose is closely associated with hemicelluloses, which are branched polymers composed of pentose and hexose sugar monomers. 
Their relative amounts vary markedly with species [4]. Lignin occurs throughout the plant cell wall, but is concentrated in the middle lamella and the primary cell wall. It is polymerized from phenylpropane units, and is of high complexity. Its native three dimensional structure is very difficult to analyze, and varies with plant species [5]. Some species of biomass, e.g. grasses, contain high amounts of extractives, such as waxes, which are of hydrophobic nature, and located in the plant's cuticula, and have a protective function. The wax consists mainly of a mix of long chain fatty acids, fatty alcohols, sterols and alkanes [6,7]. Spruce is known to contain tall oil which is a composition of rosins, unsaponifiable sterols, resin acids, fatty acids fatty alcohols, some sterols, and other alkyl hydrocarbon derivates [8].

Biomass pellets are produced in pellet mills by pressing the biomass through cylindrical shaped press channels in which the biomass is exposed to high pressure and heat that arises from the high friction between the biomass and the press channel walls. Detailed studies describing the pelletizing process, its variables, and the physical forces involved in the pellet formation, have been published elsewhere [9-12].

Little work has been done studying the fundamental forces keeping a biomass pellet together. Nevertheless, different bonding mechanisms are suggested in literature and more information can be transferred from related areas such as wood-technology and materials science. Rumpf [13] was, to the best of the authors' knowledge, the first who studied the binding mechanisms in biomass granules and agglomerates. He suggested different mechanisms such as covalent bonds between adjacent particles due to chemical reactions, attractive forces such as hydrogen bonding or van der Waals forces, and mechanical interlocking between fibers and particles.

A technology closely related to biomass pelletization is the manufacturing process of hardboards, in which wood fibers and fiber bundles are pressed into boards of high density by applying pressure and heat as high as 200-220 ${ }^{\circ} \mathrm{C}$. Back [14] has reviewed the binding mechanisms in hardboard manufacturing in detail. Inter-fiber bonding in wood-based materials is mainly due to non-covalent bonds, especially hydrogen bonds, between adjacent hemicelluloses, and/or amorphous cellulose domains, which possess numerous hydroxyl groups. Van der Waals forces are considered of some importance too, but form much weaker bonding. The formation of covalent bonds between wood polymer chains is possible to a minor extent during hot pressing reactions, with lignin being the most reactive polymer taking part in auto-oxidation reactions. It is important to remember that hardboards are made of fibers and fiber bundles as opposed to the particle structure of pellets.

Kaliyan and Morey [15] reviewed the main factors affecting the strength and durability of pellets, and suggested suitable processing conditions. In their more recent study, Kaliyan and Morey [16] investigated the binding mechanisms in roll-press briquettes made from switch grass and corn stover, using scanning electron- and fluorescence microscopy of the fracture surface. They concluded that bonding between particles is mainly due to 
solid bridge formation by natural binders such as lignin and proteins in the biomass that have been softened during the pelletizing process, and form durable particle-particle bonding. At higher temperatures, they expect an increased interfacial area between adjacent particles resulting in larger adhesive strength due to van der Waals forces, hydrogen bonding, mechanical interlocking and interdiffusion. Interdiffusion indicates the flow of the amorphous polymer molecules from one biomass particle to the adjacent particles, resulting in what Kaliyan and Morey [16] refer to as solid bridges.

The mechanical properties of lignocellulosic polymers, i.e. strength and stiffness, are strongly affected by moisture content and temperature. Lignin and hemicelluloses are essentially thermoplastic polymers, whereas cellulose is partly crystalline with highly ordered crystallites interrupted by amorphous, disordered regions. For an amorphous polymer, the main softening temperature is of high importance, since many properties, e.g. the elastic modulus, change dramatically with the material passing from a glassy into a rubbery state. The softening point is usually referred to as the glass transition temperature $\left(\mathrm{T}_{\mathrm{g}}\right)$. The higher the temperature above the $\mathrm{T}_{\mathrm{g}}$, the greater and easier is the flow of these molecules. When passing the $T_{g}$, the inter-molecular bonding is reduced, while the chain mobility and the free volume is increased to such an extent that the polymer chain ends and the backbone are able to rotate around their own axis. As a consequence, the viscosity of a polymer passing from a glassy into a rubbery state drops significantly, resulting in pronounced flow characteristics. This enables the interdiffusion of polymer chain ends and segments between adjacent fibers, and the establishment of new secondary bonds and entanglements, once the polymer is cooled down below the $\mathrm{T}_{\mathrm{g}}$. The idea of a softening point is of course a somewhat simplified picture. In reality, the polymer backbone, chain ends, etc. are those of a heterogeneous material with a distribution of molecular mass, chain length etc., and the transition occurs over a temperature range.

Salmen [17] and Irvine [18], have studied the softening of hemicelluloses extracted from wood and have shown that their glass transitions depend largely on moisture content. Under water-saturated conditions, their glass transitions are below room temperature. Furthermore, $T_{g}$ varies with chemical composition. For instance, the existence of flexible side groups lowers the transition temperatures, by reducing molecular packing (interbackbone interaction) efficiency.

The $\mathrm{T}_{\mathrm{g}}$ of lignin varies substantially depending on its origin [19]. Hardwood lignins have fewer phenolic hydroxyl groups, and a substantially more methoxyl groups [20], resulting in a significantly lower softening temperature of hardwood lignin than softwood lignin [19]. The $\mathrm{T}_{\mathrm{g}}$ of lignin varies also considerably, depending on wood species and the moisture content and ranges anywhere between 50 and above $100{ }^{\circ} \mathrm{C}[17,18,21,22]$. 
In material science, fracture surfaces are a commonly studied to determine the type and quality of adhesive bonding [23]. In the present work, we have studied the fracture surface of fuel pellets prepared from different biomass types to obtain deeper insight into the bonding mechanisms that hold a biomass pellet together. This will help in selecting optimum processing conditions for producing strong pellets and low process energy consumption.

Fuel pellets were made from beech, spruce and straw, which represent the three most common classes of biomass used for fuel pellet production, i.e. hardwoods, softwoods and grasses, respectively. To study the effect of temperature on the binding mechanism, pellets were prepared at $20{ }^{\circ} \mathrm{C}$ and $100{ }^{\circ} \mathrm{C}$, and their failure mechanisms compared using scanning electron microscopy (SEM). These temperatures were selected in order to obtain different levels of bonding: One $\left(20^{\circ} \mathrm{C}\right)$, with poor bonding and low strength, and another one $\left(100{ }^{\circ} \mathrm{C}\right.$, which is the typical temperature in commercial pellet production processes) with improved bonding and strength. The different failure mechanisms will provide insight into the type of particle-particle interactions present. The integrity of the pellets was evaluated using a compression test, and the resulting strength was related to the bonding mechanisms. Attenuated Total Reflectance Fourier Transform Infrared Spectroscopy (ATR-FTIR) was used to obtain more information about the chemical structure of the fracture surface. The combination of SEM, strength, and surface chemical information, will give insights into ways to improve strengths and integrity of pellets from various sources.

\section{Methods}

\subsection{Materials}

Three different raw materials were used for the present study: European beech (Fagus sylvatica L.) representing the class of hardwoods, Norway spruce (Picea abies Karst), a common softwood, and wheat straw (Triticum aestivum L.) from local Danish farmers as a representative for grass type biomass. The materials had a particle size between 1 to $3 \mathrm{~mm}$ in diameter and the moisture content was adjusted to about $10 \mathrm{wt} \%$ by adding water using a spray bottle and subsequent incubation in an air tight plastic box for one week. 


\subsection{Chemical Analysis}

The moisture content of the raw materials was determined using a moisture analyzer (MA 30, Sartorius, Germany) at $105^{\circ} \mathrm{C}$. The samples were dried in vacuum at $40{ }^{\circ} \mathrm{C}$ for 2 days, and milled to $<1 \mathrm{~mm}$ particle size. The composition of the raw materials were analysed using a two step strong acid hydrolysis, according to the United States National Renewable Energy Laboratory [24]. Monosaccharides (D-glucose, D-xylose and Larabinose) were quantified according to Kristensen et al. [25], using high-performance liquid chromatography (HPLC) (Summit system, Dionex, USA) equipped with an RI-detector (Shimadzu, Japan). Klason lignin content was determined based on the filter cake, subtracting the ash content after incinerating the residues from the strong acid hydrolysis at $550{ }^{\circ} \mathrm{C}$ for $3 \mathrm{~h}$ [24]. For extractives analysis, about 6 g per sample were soxhlet extracted in acetone for 3 hours, and subsequent calculation of the dry matter loss.

\subsection{Pellet preparation}

The pellets were prepared using a single pellet press (constructed at the workshop of the Technical University of Denmark). The press consists of a cylindrical die $7.8 \mathrm{~mm}$ in diameter, made of hardened steel, lagged with heating elements and thermal insulation. The temperature is controlled using a thermocouple connected to a control unit. The end of the die is closed using a removable backstop. Pressure is applied using a metal piston and a compression tester (TT-CM, Instron, USA). The compression force is measured using a $50 \mathrm{kN}$ load cell, connected to a computer and data analysis software. The die was rinsed with acetone, and wiped clean using a paper towel before each use, and when changing raw materials. To simulate the pelletizing process within a commercial pellet mill, the pellet has to be built up in sequential layers [11]. Biomass was loaded stepwise in amounts less than $0.25 \mathrm{~g}$ into the unit, and then compressed at a rate of $2 \mathrm{~mm} / \mathrm{s}$ until a maximum pressure of 200 MPa was reached. The pressure was released after five seconds, the piston removed, and more biomass was loaded and compressed until the pellet had the desired length of $16 \mathrm{~mm}$. This results in a layered structure, similar to pellets obtained by commercial units, although there are some differences. The most significant difference is that the lower part of the pellet is pressed repeatedly, and higher layers are pressed fewer times- the top layer is pressed only once. The pellets were removed from the die by removal of the backstop and pushed out by applying pressure on the pellet using the compression tester at a compression rate of $2 \mathrm{~mm} / \mathrm{s}$. 


\subsection{Mechanical testing}

The internal strength of the manufactured pellets was analyzed by compression testing and determined as the force at break according to the method used by Nielsen et al. [12]. Pellets $16 \mathrm{~mm}( \pm 1 \mathrm{~mm})$ in length, and between 7.9 and $8.2 \mathrm{~mm}$ in diameter were manufactured in a single pellet press, cooled down to $22{ }^{\circ} \mathrm{C}$ and directly tested afterwards. The pellets were placed on their side (the pellet's cylindrical shape oriented horizontally) in a compression tester (TT-CM, Instron, USA) using a disc shaped metal probe, $50 \mathrm{~mm}$ in diameter, attached to a $50 \mathrm{kN}$ load cell. The test was run at a compression rate of $20 \mathrm{~mm} / \mathrm{min}$, and stopped after pellet failure. The average force at break and its standard deviation were calculated based on at least 5 tests per sample.

\subsection{Scanning electron microscopy (SEM)}

SEM was used to study the bonding mechanism of the prepared biomass pellets by fracture surface analysis of failed pellets. The compression test resulted in total disintegration of the pellets, and therefore fracture surfaces were prepared by manually breaking a pellet into two parts. Care was taken to replicate the way each pellet was fractured and that it took place in the same region. A tiny notch was cut in center of the pellet using a razor blade, and the pellets snapped into two. Care was taken to look at the surface a little distance from the end of the notch. The two parts of the fractured pellet were attached to metal stubs using conductive carbon paste (Leit-C, Neubauer Chemikalien, Germany) that was carefully applied below and on all sites of the sample to prevent electric charging of the specimen. The upper surface was coated with a thin layer of palladium and gold using a sputter coater (SC7680, Polaron, United Kingdom). Electron micrographs were recorded using a scanning electron microscope (FEI Quanta 200, FEI Company, The Netherlands) operated at 12.5-20 kV. Multiple samples were observed for each type of pellet.

\subsection{Attenuated total reflectance infrared spectroscopy (ATR-FTIR)}

ATR-FTIR spectra of the fracture surface and raw material surface were recorded using a Fourier transform infrared spectrometer (Nicolet 6700 FT-IR, Thermo Electron Corporation, USA), equipped with a temperature adjustable ATR accessory (Smart Golden Gate diamond ATR accessory, Thermo Electron Corporation, USA), equilibrated at $30{ }^{\circ} \mathrm{C}$. Five measurements per sample were performed. To ensure good contact with the diamond surface, all hard, solid samples were pressed against it, using a metal rod and consistent mechanical pressure.. 
All spectra were obtained with 200 scans for the background (air), 100 scans for the sample and with a resolution of $4 \mathrm{~cm}^{-1}$.

To analyze the wax in wheat straw, $10 \mathrm{~g}$ of wheat straw was placed in a bottle with $150 \mathrm{ml}$ of hexane at ambient conditions. Hexane is a very effective solvent for removing wax from straw with only a limited amount of other co-extractives being removed [7]. The bottle was closed with a cap, and then shaken. This was left for about 72 $\mathrm{h}$ with occasional shaking. The supernatant liquid was then placed in a beaker with a large surface area to facilitate quick evaporation of the hexane. The volume of hexane was reduced by a factor of $\sim 20$, to concentrate the wax. This solution was then placed drop wise $(\sim 1 \mu \mathrm{l})$ on the diamond crystal of the ATR Accessory, and allowed to evaporate after every drop. Spectra of the film formed on the crystal were measured.

\section{Results and Discussion}

Table 1. Chemical composition of raw materials:

\begin{tabular}{|l|l|l|l|l|l|}
\hline Biomass type & Cellulose (\%) & Lignin (\%) & Hemicellulose (\%) & Extractives (\%) & Ash (\%) \\
\hline Beech & 38.7 & 19.3 & 27.6 & 0.6 & 0.6 \\
\hline Spruce & 41.3 & 21.6 & 22.2 & 1.8 & 0.6 \\
\hline Straw & 37.8 & 29.6 & 19.1 & 4.4 & 4.6 \\
\hline
\end{tabular}

Table 1 shows the composition of the three raw materials. (Note: the sum does not add to 100 since some elements or substances have not been evaluated using the method, e.g. proteins, pectin etc.). The cellulose content appears similar in all cases. In case of the wood species, the spruce has a higher amount of lignin than the beech. The amount of extractives in the straw is much higher than in the wood species (Table 1), most likely due to the high amounts of waxes found in its protective cuticula. 


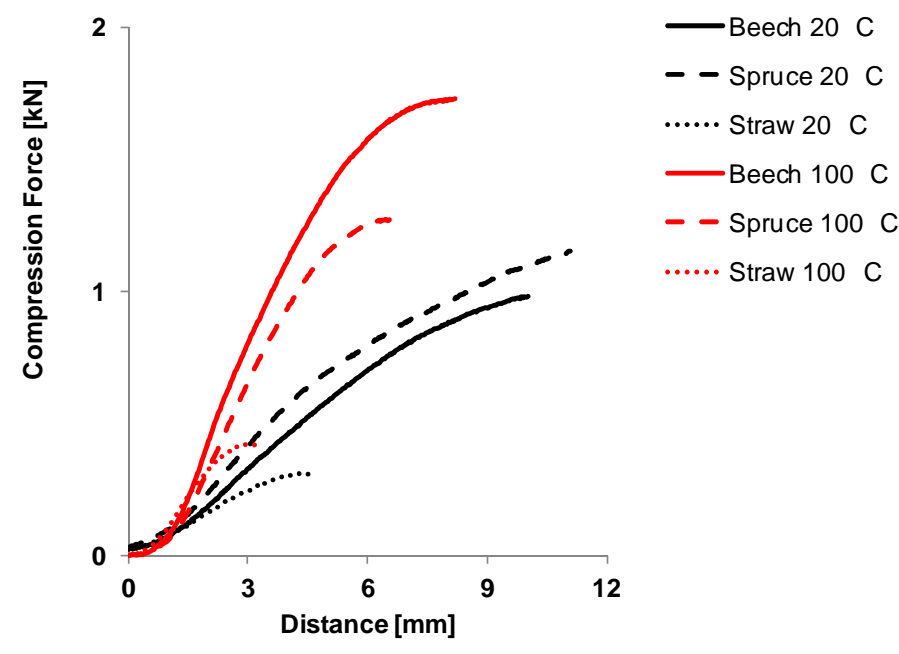

Figure 1. Typical compressive force versus distance curves of different biomass pellets prepared at $20{ }^{\circ} \mathrm{C}$ and $100^{\circ} \mathrm{C}$.

Table 2. Compression strength and their respective standard deviations of biomass pellets.

\begin{tabular}{|l|l|l|}
\hline Material & Temperature $\left({ }^{\circ} \mathbf{C}\right)$ & Force at break (kN) \\
\hline Beech & 20 & $0.93 \pm 0.13$ \\
\hline Beech & 100 & $1.53 \pm 0.18$ \\
\hline Spruce & 20 & $1.09 \pm 0.08$ \\
\hline Spruce & 100 & $1.27 \pm 0.13$ \\
\hline Straw & 20 & $0.24 \pm 0.06$ \\
\hline Straw & 100 & $0.37 \pm 0.05$ \\
\hline
\end{tabular}

Figure 1 shows the force-distance curves for a typical set of samples, and in Table 2 the average compression force at break and its standard deviation are provided. From first glance, it is obvious that the pellet strengths are higher for the pellets prepared at $100{ }^{\circ} \mathrm{C}$ than at $20^{\circ} \mathrm{C}$. There are indications that spruce pellets produced at 20 ${ }^{\circ} \mathrm{C}$ are more stable than beech pellets produced at the same temperature, although the difference is not significant. Pressing at $100^{\circ} \mathrm{C}$, produces stronger pellets from beech compared to spruce. The wood pellets have significantly higher compressive strengths than the straw pellets, at both $20^{\circ} \mathrm{C}$ and $100{ }^{\circ} \mathrm{C}$. Nielsen et al. [26] 
have reported that the pellet strength might be connected to the extractives content and that the pellet strength decreases with increasing extractives content. The present study is in consistence with this conjecture.

Pellet strength as well as fracture surface analysis give insights into the level and type of internal bonding.

Breaking the pellets using the low speed in the compression test and the higher speed of breaking the pellet manually may have different mechanisms of failure since the polymers show viscoelastic behavior. However, the compressed pellets disintegrated during the strength tests and were thus difficult to photograph using the SEM. However, we believe there will be significant similarities so that we can get some valuable information using this method. Secondly, during transport of the pellets, they will undergo a wide variety of failures, and some of these failures will be similar to our test method.

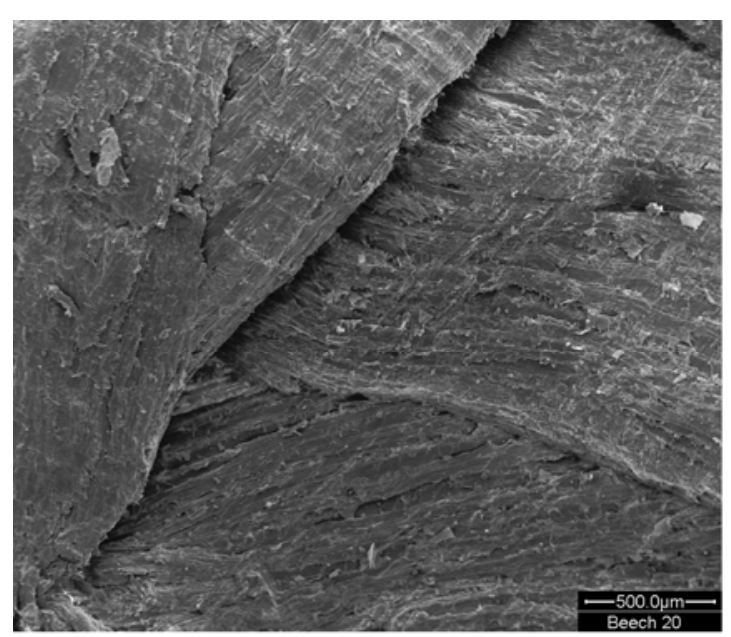

a

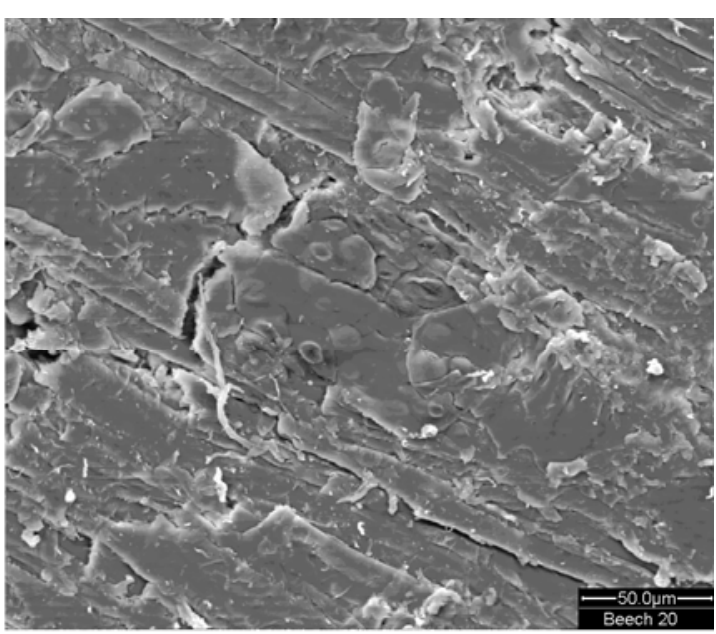

b

Figure 2. Fracture surface of beech pellets manufactured at $20{ }^{\circ} \mathrm{C}$ at low (a) and higher magnification (b). 

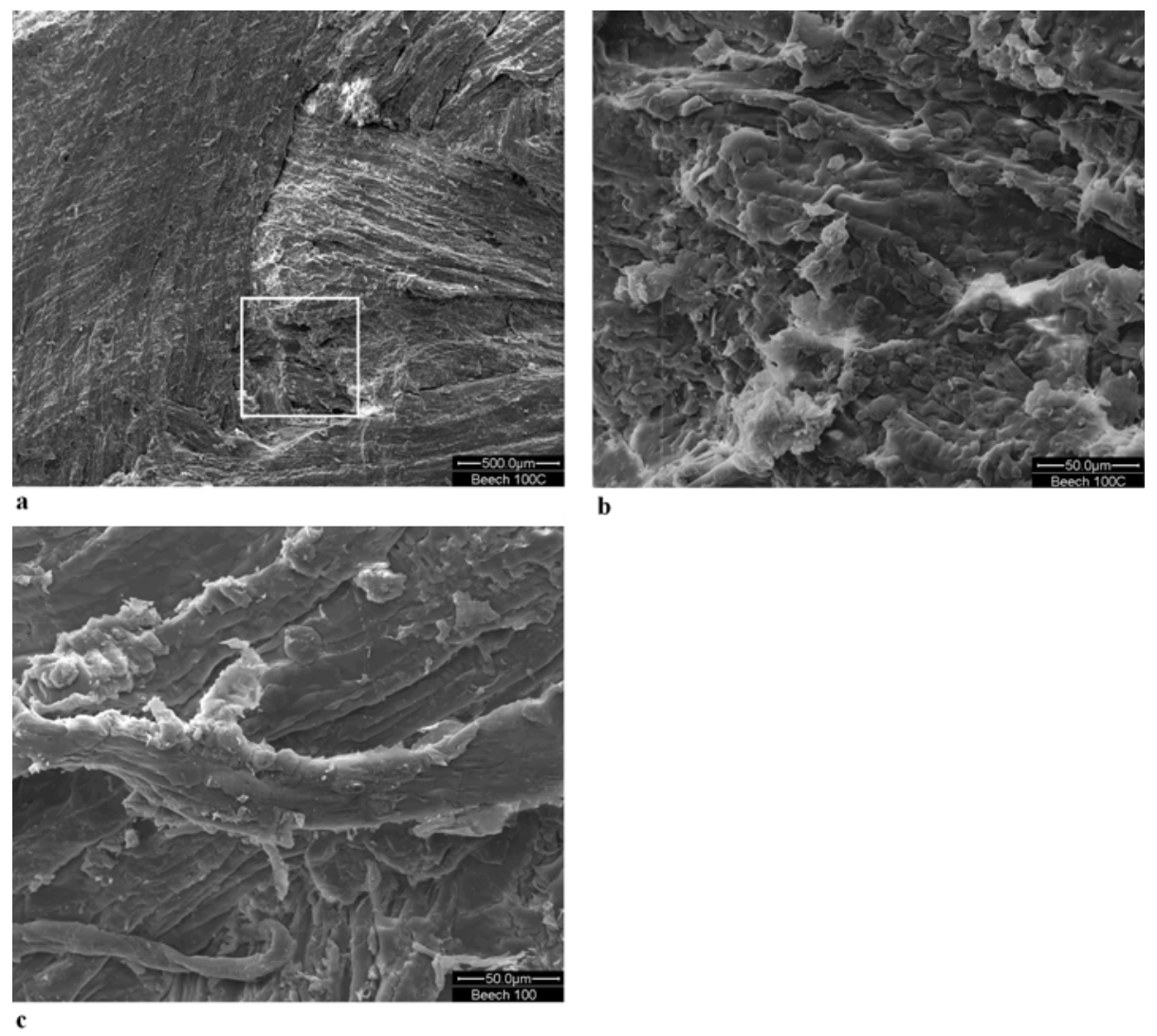

Figure 3. (a) Areas of a brittle and also cohesive fracture (in box) of beech pellets at $100{ }^{\circ} \mathrm{C}$, and (b) high magnification showing cohesive failure of the solid bridge, (c) fibers that were torn out during fracture.

Comparing the fracture surfaces of beech pellets prepared at $20^{\circ} \mathrm{C}$ (Figure 2) and $100{ }^{\circ} \mathrm{C}$ (Figure 3), significant differences can be seen. First, the inter-particle gaps and voids seen in Figure 2a are an indication of poor adhesion between adjacent particles, and/or spring back effects, as reported earlier [16, 27]. Higher magnifications (Figure 2b) shows weak inter-particle bonding which led to brittle failure.

In the case of beech pellets produced at $100{ }^{\circ} \mathrm{C}$, Figure 3a shows only small, inter-particle distances and no evidence of a spring back effect, which is a sign of good inter-particle adhesion. The fracture surface of the pellet contains different regions where the failure mechanism is less or more energy intensive. Most of the surface is relatively flat, which is indicative of a lower energy absorbing failure mechanism, probably a result of bonding limited to van der Waals and hydrogen bonding. Some of the area marked by the white box in Figure 3a, shows strong indications for cohesive failure mechanisms. Higher magnification of a similar area (Figure $3 b$ ) indicates that an energy intense fracture mechanisms results in an uneven surface, indicative of cohesive failure of the solid lignin bridge. Hemicelluloses can also flow and create solid bridges, but since they are low 
molecular weight polymers (low molecular entanglement lengths), they do not absorb much energy, and have low cohesive strengths compared to lignin. Figure $3 \mathrm{c}$ shows fiber ends and particles sticking out of the surface as a result of adhering structures being torn apart, indicating very high energy absorption due to excellent adhesion between adjacent particles.
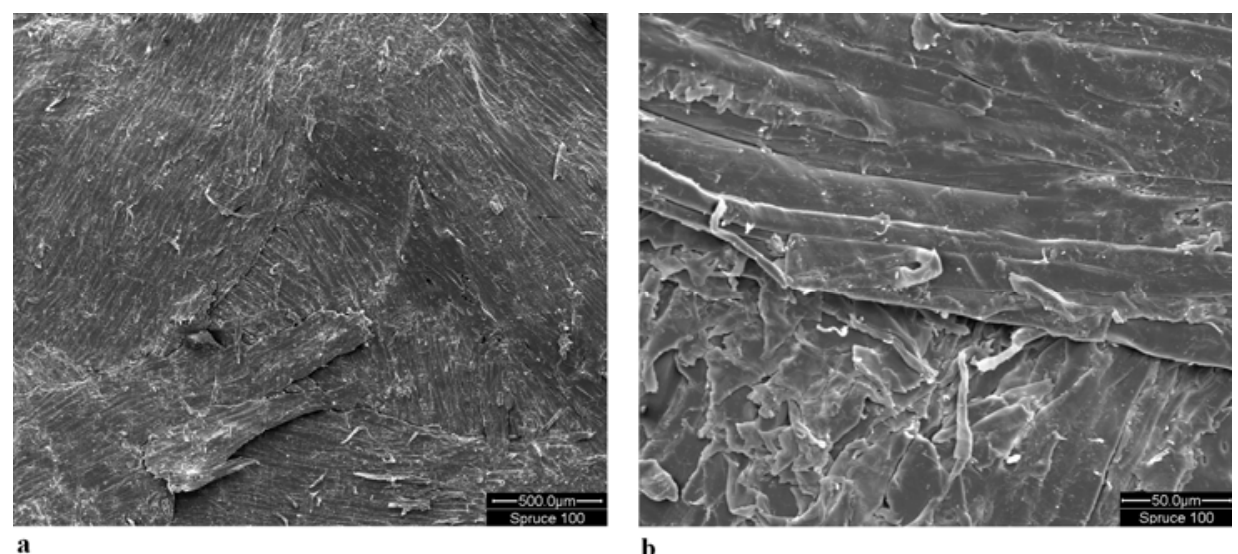

Figure 4. Fracture surfaces of spruce pellets manufactured at $100{ }^{\circ} \mathrm{C}$ at low (a) and high (b) magnification

In the case of spruce pellets prepared at $100{ }^{\circ} \mathrm{C}$, the failure surface (Figure 4) is more uniform and flat, having less surface area compared to beech pellets. This suggests adhesive failure between adjacent particles. SEM micrographs showed no signs of solid bridges formed on the spruce fracture surface. Due to the higher $T_{g}$ of the softwood lignin, the pressing conditions were not conducive (low moisture, and/or low temperature) to lignin flow and the creation of solid bridges. In such cases, H-bonding and van der Waals forces (and some mechanical interlocking) are the primary mechanism of bonding.

The higher strength of beech pellets compared to spruce can be explained by the different types of lignin on the surface, since the $T_{g}$ of lignin from hardwoods are lower than the softwoods [19]. At $100{ }^{\circ} \mathrm{C}$ it is likely that beech lignin flows more than spruce lignin, and fills cracks and crevices in the pellet, and enhancing interparticle interfacial area as well as creating solid bridges in some areas. Covalent bond formation between particles that sometimes occurs in hard boards at high temperatures [14], are unlikely to occur in either type of wood pellets at the relatively low temperature of $100^{\circ} \mathrm{C}$. 


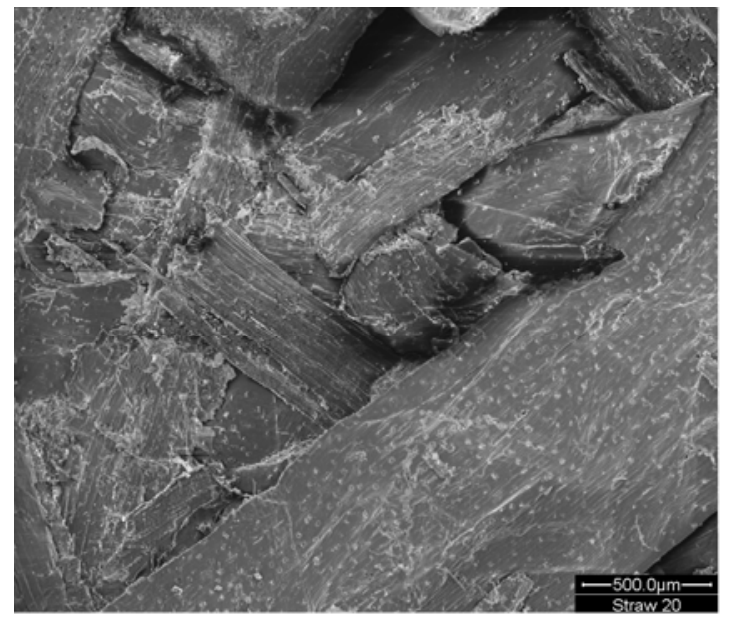

a

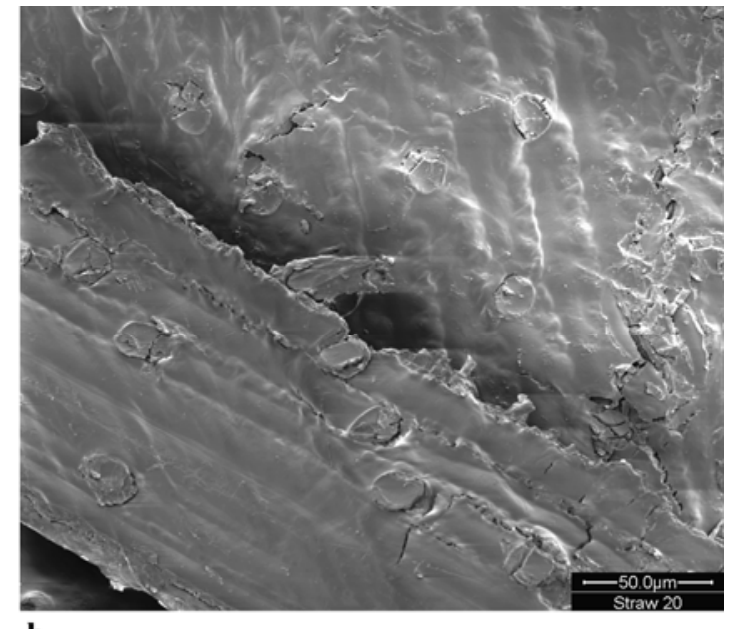

b

Figure 5. Fracture surfaces of straw pellets prepared at $20^{\circ} \mathrm{C}$ at low (a) and high (b) magnification.

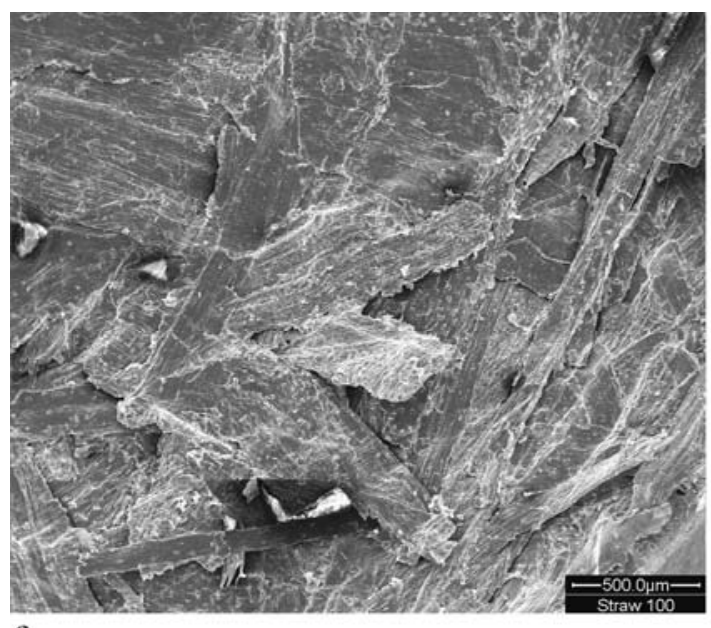

a

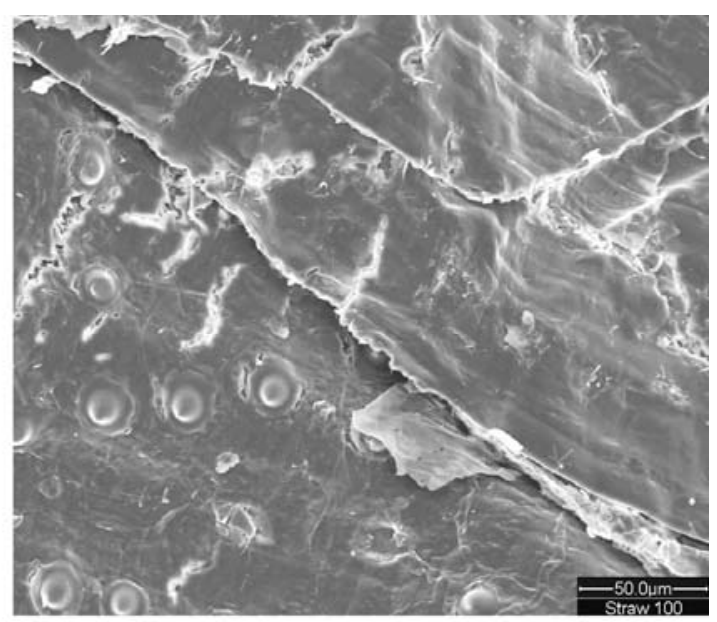

b

Figure 6. Fracture surfaces of straw pellets prepared at $100{ }^{\circ} \mathrm{C}$ at low (a) and high (b) magnification.

The compression strengths of straw pellets are significantly lower than for wood pellets (Figure 1 and Table 2), which is in good accordance with the fracture surface characteristics of the failed straw pellets prepared at $20^{\circ} \mathrm{C}$ (Figure 5) and $100{ }^{\circ} \mathrm{C}$ (Figure 6). The fracture surfaces of straw at $20{ }^{\circ} \mathrm{C}$ are very different from the corresponding surfaces of wood. There are significant gaps and voids between the adjacent straw particles, indicating that there is very little plastic flow of the amorphous plant polymers in the particles, and there is possibility of high elastic spring back, as has been reported recently [16] for other types of grassy biomass. 
Secondly, the high amount of extractives, such as waxes found in the cuticula of the straw (Table 1), will reduce the level of hydrogen bonding between adjacent particles. This, as well as the small interfacial contact area results in poor pellet strengths (Table 2). Two scenarios are possible: the failure is localized either in the waxy layer or at the interface of the waxy layer and the particle. Looking at the SEM micrographs $\left(100{ }^{\circ} \mathrm{C}\right.$ samples $)$, it is difficult to gauge whether the failure was adhesive (only van der Waals forces between the waxy layer and the particle), cohesive failure (of the weak waxy layer on the surface itself), or a combination of both mechanisms. In general, if the thickness of the waxy layer is sufficient (several layers of wax molecules), cohesive failure of the wax layer is considered to be more likely. This is sometimes referred to as a weak boundary layer (WBL) and was first introduced by Bikerman $[28,29]$. This concept has recently been extended into two distinct failure modes by Stehr and Johansson [30]: a mechanical weak boundary layer (MWBL), and a chemical weak boundary layer (CWBL). The concept of CWBL relates to the cohesive failure of the low molecular weight (e.g. wax), and the thickness can be on the molecular level, while the concept of MWBL is macroscopic, caused by machining of the wood surface or, for example UV-degradation of the wood surface Comparing the fracture surfaces of straw pellets prepared at $20{ }^{\circ} \mathrm{C}$ (Figure 5) and $100{ }^{\circ} \mathrm{C}$ (Figure 6), some differences are observed. There is more interfacial contact area at $100{ }^{\circ} \mathrm{C}$, possibly due to the fact that straw has a significant amount of both hemicelluloses and lignin that possibly can soften, and makes the straw particles more flexible at elevated temperatures. So far, no data is available in literature on the $T_{g}$ of amorphous polymers in wheat straw and its dependence on temperature and moisture content. However, the strength data suggests that wax dominates the fracture process. The pellet strength remains significantly lower than the wood pellets, although it has increased at $100{ }^{\circ} \mathrm{C}$ compared to $20^{\circ} \mathrm{C}$. The effect of proteins on the surface is not clear yet. Kaliyan and Morey [16] suggest it can enhance bonding, while Stehr and Johansson [30] suggest it could cause a CWBL. For biomass with high protein content, further work is needed to understand its effect on inter-particular bonding. 


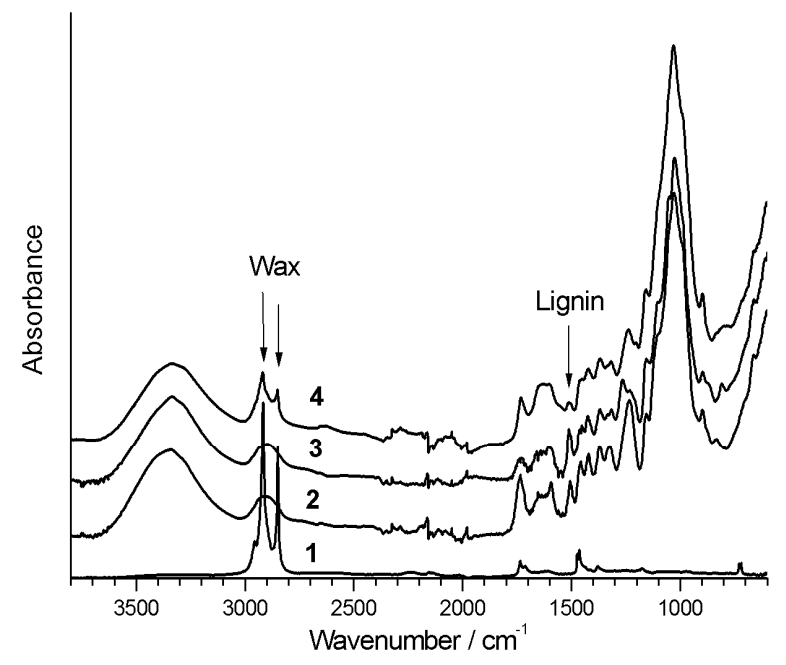

Figure 7. ATR-FTIR spectra of the fracture surface of pellets pressed at $100{ }^{\circ} \mathrm{C}$. (1) Straw extractives (wax), (2) beech, (3) spruce and (4) straw. The spectra were displaced vertically for clarity. The spectrum (absorbance) of wax is reduced by a factor of 2 .

The surface of the fractured samples were analyzed by ATR-FTIR spectroscopy, where the signal mainly originates from the outer $\sim 1 \mu \mathrm{m}$ sample surface layer with no contribution from depths much greater than $1 \mu \mathrm{m}$. Figure 7 (1) shows the spectra of the extractive from straw (i.e. wax), and one can clearly see two peaks, that are the relatively narrow $\mathrm{CH}$ (C-H bonds within a methyl group) stretching bands at 2850 and $2920 \mathrm{~cm}^{-1}$ [31] caused by wax. The main distinguishing features of the straw (4) versus wood samples (2) and (3) in Figure 7, are the two wax layer $\mathrm{CH}$ stretching bands [31], which are not observed for the wood samples. Furthermore, the straw fracture surface has a relatively small surface layer concentration of lignin, which is deduced from the weakness of the lignin $1510 \mathrm{~cm}^{-1}$ band $[32,33]$ relative to the strong $1030 \mathrm{~cm}^{-1}$ band, which is dominated by the cellulose component. Thus the ATR-FTIR results show that the chemical nature of the straw sample surfaces is very different from the wood samples, with a significant waxy layer and less surface The concentration is by a factor $\sim 3-4$ lower, compared to the wood fracture surfaces. This information adds to the argument that the low failure strength for straw pellets was due to poor inter-particle bonding and/or the low cohesive strength of the wax. Less lignin on the surface of the straw may also be detrimental to the adhesive strength. 
No evidence of alkyl $\mathrm{CH}$ stretching bands was observed in the spectra of the spruce pellets at $100{ }^{\circ} \mathrm{C}$, indicating that the temperature was not high enough for the tall oil to migrate to the fiber surface. Higher temperatures may result in the migration to the surface, and even a few monolayers of the oil can result in dramatically lowered adhesive bonding [34].

In the case of the wood pellets, a combination of suitable moisture contents, along with appropriate temperatures and pressures, could result in higher strength pellets for both beech and spruce pellets. The addition of suitable plasticizers (others than water) and the use of appropriate temperatures could also result in higher pellet strength and lower process energy consumption. However the costs of the plasticizer, its combustion properties and environmental impacts have to be considered. Higher temperatures, higher moisture content, and the use of a plasticizers or a combination of them are necessary for lignin to flow to the surface, increasing the adhesive strength in case of the wood pellets. The failure that would result in the highest strength and toughness would be similar to the one seen in Figure 3c, where the adhesion is so strong that particle failure occurs. Consistent coverage of lignin throughout the surface is probably the key to good quality pellets.

However, care should be taken not to increase the temperature to a level where extractives such as tall oil or other low molecular weight molecules can migrate to the particle surface and limit the adhesion mechanisms to van der Waals forces, which will result in low pellet strengths. The migration of low molecular weight molecules is not uncommon in traditional wood-based formaldehyde boards where heat treatment can result in a thin layer of hydrophobic extractives on the fiber surface, which drastically limits adhesion mechanisms and reduces bonding [34-36].

In case of the straw, the presence of waxes makes the process of pressing strong pellets more difficult. Preliminary studies indicate that even at $200{ }^{\circ} \mathrm{C}$ the $\mathrm{CH}$ stretching bands can be seen. Removal of the wheat straw wax would be ideal but the costs have to be justified. A bio-refinery concept, where the wax in the straw is extracted as a high value raw material used in cosmetics, polishes, etc. [7, 37], and the rest used for pellets is worth an evaluation.

\section{Conclusion}

Both the compression strength, and the fracture surface analysis of pellets pressed at $20{ }^{\circ} \mathrm{C}$ and $100{ }^{\circ} \mathrm{C}$ reveal important information about the bonding mechanisms within a biomass pellet. At $20{ }^{\circ} \mathrm{C}$, all pellets have rather 
poor mechanical strength and fracture surface analysis shows that there is only weak bonding between adjacent particles in the pellet. In case of the wood pellets, the bonding is a combination of van der Waals forces and Hbonding, while the presence of wax on the straw surface results in poor adhesive strength (dominated by van der Waals forces) ascribed to a weak waxy boundary layer. Pellets produced at $100^{\circ} \mathrm{C}$ have a greater mechanical strength and in case of the beech pellets solid bridges between adjacent particles were observed. It is suggested that those bridges form because of lignin softening and interdiffusion resulting in higher energy absorbing mechanisms during failure. Spruce at $100{ }^{\circ} \mathrm{C}$ does not show solid bridge formation, which may be due to the fact that the higher lignin $\mathrm{T}_{\mathrm{g}}$ of spruce compared to beech, does not allow sufficient lignin flow. Higher temperatures, and higher moisture contents or both are necessary for the spruce lignin to flow and contribute to the strength. However, care should be taken to ensure that hydrophobic tall oil does not migrate to the surface at these temperatures and create a weak boundary layer in which inter-particle, van der Waals forces dominate. The chemical composition of surface layers, especially the concentration of oleophilic compounds, has been shown to influence the inter-particle bonding. A high concentration of wax at the straw samples surfaces, combined with a relatively low lignin concentration, results in poor adhesion and low compression strength of the straw pellets, both at $20{ }^{\circ} \mathrm{C}$ and $100{ }^{\circ} \mathrm{C}$. This work provides insights on how an in depth analysis of the adhesive mechanisms and failure analysis can help design pellets optimized for cost and strength.

In future studies it, would be interesting to investigate the effect of moisture content and temperature, on the flow properties of the biomass polymers during pelletization, the resulting pellet strength, and inter-particle bonding. In this context, the softening properties of straw lignin and how properties depend on moisture content and temperature will be particularly useful.

\section{Acknowledgements}

The present study was conducted under the framework of the Danish Energy Agency's EFP project: “Advanced understanding of biomass pelletization" ENS-33033-0227. The authors wish to thank Vattenfall AB, DONG Energy A/S and the Danish Energy Agency for funding. The authors wish to acknowledge the advice and help provided by Joanna Møller Nielsen for the chemical analysis of the biomass. 


\section{References}

[1] Mani S, Sokhansanj S, Bi X, Turhollow A. Economics of producing fuel pellets from biomass. Appl Eng Agric 2006;22:421-6.

[2] Peksa-Blanchard M, Dolzan P, Grassi A, Heinimoe J, Junginger M, Ranta T, et al. Global wood pellets market and industry: Policy, drivers, market status and raw material potential, IEA Bioenergy Task 40. Paris: International Energy Agency; 2007.

[3] Voulgaraki S, Balafoutis A, Papadakis G. Legal framework for MBP utilisation. Athens: Agricultural University of Athens, Dept. of Natural Resources and Agricultural Engineering; 2007.

[4] Miller RB. Structure of wood. In: Wood handbook - Wood as an engineering material. Madison: United States Department of agriculture - Forest Service - Forest products laboratory; 1999.

[5] Fengel D, Wegner G. Wood - chemistry, ultrastructure, reactions. Remagen: Kessel Verlag; 1983.

[6] Hamilton RJ. Analysis of waxes. In: Waxes: chemistry, molecular biology and functions. Dundee: The Oily Press; 1995.

[7] Deswarte FEI, Clark JH, Hardy JJE, Rose PM. The fractionation of valuable wax products from wheat straw using CO2. Green Chem 2006;8:39-42

[8] Biermann CJ. Essentials of Pulp and Papermaking. San Diego: Academic Press Inc.; 1993.p.107.

[9] Nielsen NPK, Gardner DJ, Poulsen T, Felby C. Importance of temperature, moisture content, and species for the conversion process of wood into fuel pellets. Wood Fiber Sci 2009;41:414-25

[10] Holm JK, Henriksen UB, Hustad JE, Sorensen LH. Toward an understanding of controlling parameters in softwood and hardwood pellets production. Energy Fuels 2006;20:2686-94.

[11] Holm JK, Henriksen UB, Wand K, Hustad JE, Posselt D. Experimental verification of novel pellet model using a single pelleter unit. Energy Fuels 2007;21:2446-9.

[12] Nielsen NPK, Holm JK, Felby C. Effect of Fiber Orientation on Compression and Frictional Properties of Sawdust Particles in Fuel Pellet Production. Energy Fuels 2009;23:3211-6.

[13] Rumpf H. The strength of granules and agglomerates. In: Knepper WA, editor. Agglomeration. New York: John Wiley and sons; 1962, p. 379.

[14] Back EL. The bonding mechanisms in hardboard manufacture - review report. Holzforschung 1987;41:247-58.

[15] Kaliyan N, Morey RV. Factors affecting strength and durability of densified biomass products. Biomass Bioenergy 2009;33:337-59.

[16] Kaliyan N, Morey RV. Natural binders and solid bridge type binding mechanisms in briquettes and pellets made from corn stover and switch grass. Bioresour Technol 2010;101:1082-90. 
[17] Salmen L. Viscoelastic properties of insitu lignin under water-saturated conditions. J Mater Sci 1984;19:3090-6.

[18] Irvine GM. The glass transitions of lignin and hemicellulose and their measurement by differential thermal-analysis. Tappi J 1984;67:118-21.

[19] Olsson AM, Salmen L. Viscoelasticity of insitu lignin as affected by structure - softwood vs hardwood. In: Glasser, W. editor. Viscoelasticity of Biomaterials. ACS Symposium Series 489. Washington: American Chemical Society 1992.p.133-43.

[20] Sjöström E. Wood Chemistry: Fundamentals and Applications. London: Academic Press; 1983.

[21] Kelley SS, Rials TG, Glasser WG. Relaxation behavior of the amorphous components of wood. J Mat Sci 1987;22:617-24.

[22] Hatakeyama H, Hatakeyama T. Thermal properties of isolated and in situ lignin. In: Heitner C, Dimmel D, Schmidt J, editors. Lignin and Lignans: Advances in Chemistry. New York: CRC Press; 2010, p. 301.

[23] Hull D. Fractography: Observing, measuring, and interpreting fracture surface topography. Cambridge: Cambridge University Press; 1999.

[24] Sluiter A. Determination of Structural Carbohydrates and Lignin in Biomass. Golden: National Renewable Energy Laboratory; 2004.

[25] Kristensen JB, Thygesen LG, Felby C, Jorgensen H, Elder T. Cell-wall structural changes in wheat straw pretreated for bioethanol production. Biotechnol Biofuels 2008;1

[26] Nielsen NPK, Gardner DJ, Felby C. Effect of extractives and storage on the pelletizing process of sawdust. Fuel 2010;89:94-8.

[27] Odogherty MJ, Wheeler JA. Compression of straw to high-densities in close cylindrical dies. J Agr Eng Res 1984;29:61-72.

[28] Bikerman JJ. The science of adhesive joints. New York: Academic Press; 1961.

[29] Bikerman JJ. Causes of poor adhesion - weak boundary layers. Ind Eng Chem 1967;59:40-4.

[30] Stehr M, Johansson I. Weak boundary layers on wood surfaces. J Adhes Sci Technol 2000;14:1211-24.

[31] Merk S, Blume A, Riederer M. Phase behaviour and crystallinity of plant cuticular waxes studied by Fourier transform infrared spectroscopy. Planta 1998;204:44-53.

[32] Faix O. Classification of lignins from different botanical origins by FT-IR spectroscopy. Holzforschung $1991 ; 45: 21-7$.

[33] Stewart D, Wilson HM, Hendra PJ, Morrison IM. 1995. Fourier-Transform Infrared and Raman Spectroscopic Study of Biochemical and Chemical Treatments of Oak Wood. J Agri Food Chem 1995;43:2219-25. 
[34] Christiansen AW. How overdrying of wood reduces its bonding to phenol-formaldehyde adhesives - a critical review of the literature. 1. Physical responses. Wood Fiber Sci 1990;22:441-59.

[35] Nguyen T, Johns WE. Effects of aging and extraction on the surface free energy of douglas-fir and redwood. Wood Sci Technol 1979;13:29-40.

[36] Hancock WV. Effect of heat treatment on the surface of douglas-fir and veneer. Forest Products Journal $1963 ; 13: 81-8$.

[37] Deswarte FEI, Clark JH, Wilson AJ, Hardy JJE, Marriott R, Chahal SP, et al. Toward an integrated straw-based biorefinery. Biofuels Bioproducts 2007;1:245-54. 